\title{
Clinical Features and Management of Eosinophilic Asthma
}

\author{
Syabbalo $\mathrm{N}^{*}$
}

Department of Medicine and Physiology, Copperbelt University, M. C. Sata School of Medicine, Kitwe, Zambia

${ }^{*}$ Corresponding author: Syabbalo N, MB., ChB., PhD., FCCP., FRS, Professor of Medicine and Physiology, Copperbelt University, M. C. Sata School of Medicine, P. O. Box 21692, Kitwe, Zambia, Tel: +260 966 486117, E-mail: nightsyab@gmail.com

Citation: Syabbalo N (2020) Clinical Features and Management of Eosinophilic Asthma. J Respir Dis Treat 1(1): 105. doi: 10.15744/2767-4649.1.105

Received Date: January 07, 2020 Accepted Date: April 15, 2020 Published Date: April 17, 2020

\begin{abstract}
Asthma is a common chronic airway disease affecting about 334 million people worldwide, and an estimated 7 million children globally. Approximately $10 \%$ of patients with asthma have severe refractory disease, which is uncontrolled despite using high doses of inhaled corticosteroids and other modifiers. Among these patients are patients with eosinophilic asthma. Eosinophilic asthma is a phenotype of asthma that is usually very severe and persistent, with frequent exacerbations. It is characterized by the presence of high levels of eosinophils, and CD+4 Th2 cells in the lungs and airways. Eosinophils play a pivotal role in the pathogenesis and severity of asthma. Most patients with eosinophilic asthma respond to the classic stepwise guided treatment. However, 50\% of patients with eosinophilic asthma are refractory to corticosteroids and long-acting $\beta 2$-agonists. Currently, there are targeted personalized biologics for these patients. These biotherapeutics include IgE, interleukin and interleukin receptor monoclonal antibodies, they have added advantageous steroid-sparing effects.
\end{abstract}

Keywords: Eosinophilic Asthma; Asthma Phenotypes; Biomarkers; Interleukins; Monoclonal Antibodies

\section{Introduction}

Asthma is a complex chronic airway disease with several distinct phenotypes with different immunopathological pathways, clinical presentation, physiology, cormobidities, biomarker of allergic inflammation, and response to treatment [1-4]. There are several distinct proposed asthma phenotypes, such as childhood-ons et al. lergic asthma, adult-onset eosinophilic asthma,neutrophilic asthma, exercise-induced asthma (EIA), obesity-related asthma, and aspirin-exacerbated respiratory disease (AERD) [5-7]. Severe asthma represents about 5-10\% of patients with asthma, and about 50\% of these patients present with eosinophilic asthma [8-10]. The guidelines on the definition, evaluation and treatment of severe refractory asthma including eosinophilic asthma are given in detail by thethe American Thoracic Society (ATS) [11], and the European Respiratory Society (ERS) [12]. Severe asthma is defined by the joint ERS/ATS according to the following criteria [12]:

(1) Requirement with high-dose inhaled corticosteroids and a second controller (and) or systemic corticosteroid to maintain control.

(2) Refractory to treatment mentioned above.

(3) Incomplete management of cormorbidities such as sinus disease and obesity.

\begin{tabular}{|c|}
\hline Major criteria \\
\hline Treatment with continuous or near continuous $(>50 \%$ of the year) oral corticosteroids \\
\hline Need for treatment with high-dose inhaled corticosteroids \\
\hline Minor criteria \\
\hline Need for additional daily treatment with controller medication (long-acting $\beta 2$-agonist, leukotriene receptor antagonist, theophylline) \\
\hline Asthma symptoms needing short-acting $\beta 2$-agonist use on a daily or near daily basis \\
\hline Persistent airway obstruction (FEV $1<80 \%$ predicted, diurnal peak flow variability $>20 \%$ predicted) \\
\hline One or more urgent care visit for asthma \\
\hline Three or more oral steroid bursts per year \\
\hline Prompt deterioration with $<25 \%$ reduction in oral or inhaled corticosteroid \\
\hline Near fatal asthma event in past \\
\hline
\end{tabular}

Diagnosis: one major criterion plus two minor criteria; other diseases should have been excluded, exacerbating factors treated, and patient is general adherent Table 1: American Thoracic Society Criteria for Severe/Refractory Asthma 
In the Proceedings of the ATS Workshop on Refractory Asthma the delegates agreed on two major and seven minor criteria for the diagnosis of severe refractory asthma. The criteria for established diagnosis of severe asthma include fulfilling one or both major criteria and at least two minor criteria [11]. The ATS criteria for the diagnosis of severe refractory asthma are listed in Table 1.

Severe refractory asthma includes eosinophilic asthma, is characterized by frequent exacerbations, poor quality of life, and unresponsiveness to standard treatment with inhaled corticosteroids (ICSs), long-acting $\beta 2$-agonists (LABAs), and leukotriene receptor antagonists (LTRAs) [4,12,13].

It has now become part of clinical practice to use biomarkers to stratify asthma phenptypes. Biomarkers in asthma are very useful in stratifying asthma into different phenotypes, reflect the predominant immunopathological mechanisms, help to predict future risks, and identify patients who are more likely to benefit from personalized biologics, such as interleukin (IL)-5, IL-4/13, and thymic stomal lymphopoietin (TSLP) monoclonal antibody therapy [14].

\section{Eosinophilic Asthma}

Eosinophilic asthma is one of the well-defined clinical phenotype of asthma [6-8,10]. This phenotype of asthma is usually observed in adult asthmatic patients after 20 years or later, although it may occur in children $[8,10]$. It is a debilitating, severe and persistent disease, with frequent exacerbations and a worse quality of life, and has a poor prognosis [7-10,12]. Eosinophilic asthma is associated with more urgent visits to emergence rooms, hospitalization and intubation [13], and a high morbidity and a history of a near-fatal asthma in about $23 \%$ of the patients [11]. Patients with eosinophilic asthma experience persistent airflow limitation, air trapping [15], and severe symptoms despite the use of high-dose ICSs, and LABAs $[11,12,16]$. They have frequent exacerbations and are dependent on oral corticosteroids. This subgroup of patients impart a disproportionate pharmaco-economical burden [17], with the mean UK annual treatment costs reaching between $£ 2912$ and $£ 4217$ per patient [18].

Eosinophilic asthma is characterized by a high blood eosinophil count ( $\left.\geq 300 / \mu \mathrm{L} ; 0.300 \times 10^{9} / \mathrm{L}\right)$, and in induced sputum ( $\geq 2 \%$ $3 \%$ ), airway eosinophilia infiltration [19-21], and high $\operatorname{IgE}$ (total $\operatorname{IgE} \geq 200 \mathrm{kU} / \mathrm{L}$ ) [22,23], fraction exhaled nitric oxide (FeNO) [24,25], and periostin serum levels [26-28]. FeNO measurement is esteemed to be particularly useful to identify high Th2 activity. An official ATS clinical practice guideline recommends that high FeNO $\geq 50 \mathrm{ppb}$ in adults and $>35 \mathrm{ppb}$ in children can be used to indicate eosinophilic inflammation in subjects not on corticosteroid therapy [25].

In more than $50 \%$ of patients with persistent airway eosinophilia, both blood and sputum eosinophilia are associated with worse disease control, frequent exacerbations, and poor prognosis [7-10,12]. The eosinophilia assessed by sputum eosinophil count, often correlates with the severity of the disease [7-10]. Several studies have shown that the risk of severe exacerbation can be reduced by treatment with targeted precision biologics that minimized airway eosinophilia [29-31]. Thus, assessment of sputum eosinophil count can be used as a diagnostic marker and to monitor treatment [30-32].

Periostin is an extracellular matrix protein belonging to the fasciclin 1 family that has been implicated in many diseases. It is a downstream molecule of interleukin 13 airway inflammatory pathway. This pleotropic protein has been demonstrated to be increased in patients with a number of clinical conditions associated withincreased cell division, cell turnover, invasion, and angiogenesis, including cancers [33]. Therefore, serum periostin levels should be interpreted in the context of the clinical seting, and in conjunction with other biomarkers of eosinophilic inflammation, such as blood eosinophil counts.

However, serum periostin levels are good biomarkers of eosinophilic inflammation, and serum periostin levels can also be used to monitor response to treatment with biologics, such as omulizumab in patients with severe asthma [34].

\section{Clinical Features}

Eosinophilic asthma is a severe refractory disease which occurs in about $4 \%$ of adult patients with asthma [10,19], and it has no gender preponderance in the distribution [10]. It usually manifests in early adulthood with a peak incidence between 20 to 35 years [7,10,35]. The classical symptoms include recurrent episodes of wheezing, breathlessness, chest tightness, and cough. The symptoms are usually worse at night (nocturnal asthma). Cough is a frequent symptom particularly in children and it may be mistaken for an upper respiratory tract infection, or bronchiolitis. Precipitating factors include viral upper respiratory tract infection (e.g., rhinovirus), exercise particularly in cold weather, exposure to pollutants such as cigarette smoke, SO2, NO2, and ozone, and medications (Table 2). The drugs which can precipitate asthma include beta-blockers, even when administered topically as eye drops, e.g., timolol for glaucoma, aspirin and other non-steroidal anti-inflammatory drugs (NSAIDs), and angiotensin converting enzyme-inhibitors. Other medications include oral contraceptives, cholinergic agents, and prostaglandin F2 $\alpha$ [10].

\begin{tabular}{|c|}
\hline Viral upper and lower respiratory infections \\
\hline Rhinovirus \\
\hline Parainfluenza virus \\
\hline Respiratory syncytial virus \\
\hline Occupational sensitizers \\
\hline
\end{tabular}




\begin{tabular}{|c|}
\hline Viral upper and lower respiratory infections \\
\hline Isocyanate \\
Colophony fumes \\
\hline Atmospheric pollution \\
\hline Sulphur dioxide, nitrogen dioxide \\
\hline Ozone \\
\hline Irritant dusts, vapours and fumes \\
\hline Cigarette smoke \\
\hline Perfumes \\
\hline Exercise \\
\hline Food anaphylaxis \\
\hline Shrimps, peanuts, wheat allergy \\
\hline Medication \\
\hline Aspirin, non-steroidal anti-inflammatory drugs \\
\hline B2-blockers \\
\hline Angiotensin-converting enzyme (ACE) inhibitors \\
\hline Aeroallergens (rare) \\
\hline Dermatophagoides pteronyssinus \\
\hline Grass pollen \\
\hline Domestic pet dander \\
\hline Cockroaches \\
\hline
\end{tabular}

Table 2: Causes and precipitating factors for eosinophilic asthma

There is a tremendous variation in the frequency and duration of the attacks. Some patients have one or two severe attacks per year, but the majority of the patients have frequent exacerbations $[9,10]$, and some patients have severe chronic disabling symptoms [35]. Patients with mild asthma are usually asymptomatic between exacerbations, whereas patients with persistent asthma have symptoms of breathlessness and wheeze most of the time, particularly in early mornings. Nocturnal asthma is frequently reported by patients with eosinophilic asthma [13].

Apart from displaying the above clinical features, patients with eosinophilic asthma have unique clinical presentation, which differ greatly from those of the classical symptoms of childhood-onset, allergic asthma. This phenotype of asthma is less likely to be precipitated by allergens, such as grass pollen, pet dander allergens, and Dermatophagoides pteronyssinus in contrast to childhoodonset asthma [36]. Exercise-induced asthma is more common in patients with eosinophilic asthma compared to other phenotypes of asthma, and patients with eosinophilic or late-onset asthma are very sensitive to aspirin, and may have comorbid aspirin exacerbated respiratory disease (AERD) [37]. Patients with eosinophilic asthma are very susceptible to angiotensin converting enzyme-inhibitors (ACE-Is), and usually develop severe dyspnea, and bronchospasm with treatment with angiotensin converting enzyme-inhibitors [38].

Clinically the disease is very severe with frequent exacerbations to near fatal asthma which requires frequent emergency room visits and intubations [17-21]. Patients with eosinophilic asthma have a poor quality of life and worse prognosis [17-21].

Eosinophilic asthma is often associated with chronic rhinosinusitis and nasal polyposis [39,40]. Nasal symptoms and CT imaging of sinonasal involvement correlates with the severity of asthma, sputum eosinophil count and airflow limitation [40]. Medical and surgical treatment is associated with improvement in asthma control [41]. Other concomitant disorders such as gastroeosophageal reflux disease [42], and obesity [43], may make the asthma control difficult, and these comorbidities need to be treated [42,44].

Patients with eosinophilic asthma have persistent airflow obstruction characterized by constantly very low forced expired volume in 1 second (FEV1). As a result of fixed low FEV1, and FEV1/FVC ratio, eosinophilic asthma may be misdiagnosed as chronic obstructive pulmonary disease (COPD). Additionally, they have a higher bronchial responsiveness to methacholine compared to controls subjects and to patients with neutrophilic asthma.

Laboratory investigations reveal marked eosinophilia in peripheral blood, induced sputum $[13,14,16]$, and bronchial biopsy [13]. The eosinophilic infiltration most commonly affects the peripheral airways, and is associated with higher expression of transforming growth factor- $\beta$ (TGF- $\beta$ ) [45], subepithelial fibrosis and airway remodeling [46]. The structural changes also include loss of elastic recoil with increased lung compliance, most pronounced in peri-bronchiolar area, resulting in irreversible small airways obstructive disease [47]. Thismay lead to chronic airflow obstruction and severe refractory asthma which is unresponsive to corticosteroids $[13,47]$. 
Eosinophilic asthma is difficult to treat with the standards-of-care asthma control medicines and requires the use of chronic oral corticosteroids, thus, it is also referred to as corticosteroid-refractory disease or "difficult-to-treat asthma" [4,10]. The patients may require large doses of oral corticosteroids (OCSs) which may associated with the numerous serious side-effects from the glucocorticoids, such as adrenal suppression, hypertension, diabetes mellitus, hypercholesterolaemia, weight gain, osteoporosis, cataract and glaucoma $[48,49]$.

\section{Biomarkers of Eosinophilic Astha}

In the era of targeted precision medicine, it has now become clear that biomarkers are essential in the diagnosis and management of different phenotypes of asthma.Biomarkers in asthma can help stratify asthma into different phenotypes, reflect the predominant immunopathological mechanisms [50], help to predict future risks [51], and identify patients who are more likely to benefit from targeted personalized interleukin monoclonal antibodies therapy (IL-5, IL-4/13, and TSLP) [51-53]. The Th2-driven eosinophilic asthma biomarkers currently used include sputum and blood eosinophil counts, total serum IgE, the fraction of exhaled nitric oxide (FeNO), periostin, and dipeptidyl peptidase-4 (DPP-4) [14,50-57].

\section{Sputum Eosinophil Count}

Elevated sputum eosinophil counts are associated with severe asthma and increased risk of exacerbations [58]. Sputum eosinophil count correlates partially with FeNO and blood eosinophil numbers [59], and both markers can be combined in the diagnosis of eosinophilic asthma. Measurement of eosinophils in induced sputum and bronchoalveolar (BAL) fluid has been shown to be a reliable biomarker of airway eosinophilic inflammation, and induced sputum is considered as the gold standard non-invasive method for assessing airway inflammation in asthma to identify inflammatory phenotypes [60]. The recent ERS/ATS guidelines suggest that induced sputum can be used in the management of severe asthma in specialized centres with a dedicated laboratory [12]. Furthermore, the guidelines recommend using sputum eosinophil counts to adjust corticosteroid therapy [12]. Cowan et al. [61], have shown that sputum eosinophilia $\geq 3 \%$ predicts response to corticosteroids, thus, sputum eosinophil count can be used to stratify patients into eosinophilic asthma or non-eosinophilic asthma for guided personalized treatment with biologics. Sputum count is a validated biomarker for initiating biotherapeutics in patients with eosinophilic asthma [62]. Anti-IL-5 mABs, namely mepoliumab $[63,64]$, and reslizumab [65] decreased exacerbations and improved the quality of life in patents with sputum eosinophilia greater than $3 \%$. Similarly, dupilumab, a targeted mAb against IL-4R $\alpha$ that modulates the IL-4/13 pathway improved asthma control and pulmonary function in asthma patients with sputum eosinophilia ( $\geq 3 \%$ ) or blood eosinophil count of $\geq 300$ cells/ $\mu \mathrm{L}$ [66].

\section{Blood Eosinophil Count}

Blood eosinophil count is an established biomarker of severe eosinophilic asthma $[67,68]$. Patient with eosinophilic asthma have a raised peripheral blood eosinophilia $\left(\geq 300\right.$ cells $\left.\bullet \mu \mathrm{L}^{-1} ; 0.300 \times 10^{9}\right)$, and other biomarkers, including high expression of Th2 cytokines (Il-4, IL5, and IL-13) [69]. A high blood eosinophil count can be used as a marker for eosinophilic inflammation, and correlates well with poor asthma control, increased risk of exacerbations, and re-hospitalization [67,70-73]. Patients with eosinophilic asthma have a high risk of airflow obstruction, and an enhanced longitudinal decline in lung function [74,75]. They exhibiting both local and systemic eosinophilic inflammation, and have more severe asthma reflected by lower baseline pulmonary function (FEV1) [75]. They have higher bronchial hyperresponsiveness to methacholine, poor asthma control and quality of life, and a greater number of exacerbation in the year preceding measurement of blood eosinophil count and FeNO [67,71]. Analysis of patients from the Optimum Patient Care Database (OPCRD) in the UK by Price and colleagues, revealed that patients with a high blood eosinophil count $\left(\geq 0.300 \times 10^{9} / \mathrm{L}\right)$ and higher FeNO $(\geq 50 \mathrm{ppb})$ were four-times more likely to have severe exacerbations compared with patients with low eosinophil count and low FeNO [67]. Therefore, combination of blood eosinophil count and FeNO may be even a stronger markers of exacerbation risk compared with individual biomarker [67]. Both markers may be required to select patients with poor sensitivity to ICS who may require a more targeted, personalized approach of therapy [67]. Konradsen et al. [76], have also reported that paediatric patients with blood eosinophilia $\left(\geq 300\right.$ cells $\left.\bullet \mu \mathrm{L}^{-1}\right)$ have more severe asthma, more exacerbations, lower FEV1/FVC ratios, and airway hyperresponsiveness. There is a consistent relationship between blood and sputum eosinophilia in patients with eosinophilic asthma [59], and both markers are cpmplementary in the diagnosis of eosinophilic asthma.

Blood eosinophil count is readily available and inexpensive biomarker of eosinophilic asthma. It can serve as diagnostic marker to stratify different asthma phenotypes [77]. It can also be used as a prognostic biomarker and direct response to several therapeutic interventions in asthmatic patients with type 2 inflammation [77]. A baseline blood eosinophil threshold of 150 cells $\bullet \mu \mathrm{L}^{-1}$ or greater or a historical blood eosinophil threhold of $\geq 300$ cells $\bullet \mu \mathrm{L}^{-1}$ or greater will allow selection of patients who are more likely to achieve clinically significant improvement with treatment with ICSs, and anti-interleukin mAbs (e.g., anti-IL-4, anti-IL-5, antiIL-13, and anti-TSLP) [78]. Blood eosinophil counts can predict responsiveness to inhaled corticosteroids and can be used to taper the dosage of OCS, such as prednisone [79].

Baseline blood eosinophil count is useful as a biomarker to stratify patients for treatment with interleukin monoclonal antibodies, such as anti-IL-4 antibodies for mepolizumab [68,80], and reslizumab [81], anti-IL-5 receptor antibody for benralizumab [82], and 
anti-IL-4 receptor antibody for dupilumab [83]. The cut-off of blood eosinophils count is 300 cells $\mu \mathrm{L}^{-1}$ for most biologics, except the reslizumab (400 cells $\mu^{-1}$ ) [84]. There is a range of responses at different blood eosinophil levels, and patients with higher blood eosinophil levels $\left(\geq 300\right.$ cells $\left.\bullet \mu \mathrm{L}^{-1}\right)$ tending to have a better response to treatment $[84,85]$.

Blood eosinophilia is a superior assessment for detection of airway eosinophilia in patients with asthma [86], and can be used to stratify the different phenotypes asthma [86]. It is easy to obtain and correlates well with sputum eosinophilia [88], and in combination with other biomarkers such as FeNO can predict the risk of asthma exacerbations $[67,89]$. However, the concern is that the optimal threshold has yet to be standardized. Morever, eosinophil levels may be elevated due to co-existing conditions, such as hypereosinophilic syndromes, and parasitic infestations, including helminthiases, schistosomiasis and filariases, thus limiting its use as a predictive biomarker of eosinophilic asthma.

\section{Fractional Exhaled Nitic Oxide}

Nitric oxide plays an important role in lung immunobiology. It is a bronchodilator [90], vasodilator and an inflammatory mediator [91]. Gas phase nitric oxide is produced in the lung by nitric oxide synthase (NOS) during the conversion of the amino acid L-arginine to L-citrulline [92]. The biomarker fractional exhaled nitric oxide (FeNO) is produced by airway epithelial cells by inducible nitric oxide synthase upregulation during allergic inflammation [93]. The levels of FeNO reflect indirectly the inflammatory responses in the airways $[25,93,94]$. FeNO is a useful method for indirectly assessment of eosinohilic airway inflammation in adults [25,67,9496], and in children [97].

Fraction exhaled nitric oxide concentration greater than $50 \mathrm{ppb}$ is a marker for eosinophilic airway inflammation, and predicts the likelihood to respond to corticosteroids $[98,99]$. In some patients, high levels of FeNO concentration are considered a risk for exacerbations and poor disease control in adult patients treated with ICS [100-102], and may identify patients with poor response to ICSs who may benefit from targeted personalized biotherapeutics. Although both FeNO concentration and blood eosinophil count are elevated in patients with eosinophilic asthma, they only show modest correlation reflecting different activation of the Th2driven inflammatory pathways [96,103]. Price et al. [67], using patients' data from the Optimum Patient care Database (OPCRD) in the UK [104], have reported that patients with higher FeNO ( $\geq 50 \mathrm{ppb})$ and a high blood eosinophil count $\left(\geq 0.300 \mathrm{x} 10^{9}\right)$ were four-times more likely to have had severe exacerbations compared with patients with low FeNO $(<25 \mathrm{ppb})$ and low eosinophil levels $\left(<0.300 \times 10^{9}\right)$ in the year preceding the FeNO readings. They have demonstrated that the combination of high blood eosinophil count and FeNO may be even a stronger marker of exacerbation risk in patients with eosinophilic asthma compared with individual biomarkers. Because of the variations in the measurements of FeNO, it is suggested that it should be used to complement other biomarkers, particularly blood eosinophil count in the diagnosis of eosinophilic asthma [67].

The American Thoracic Society cutoff level of FeNO is commonly used in clinical practice [25]. The high FeNO cutoff has been set at $\geq 50 \mathrm{ppb}$ and the low cutoff at $<25 \mathrm{ppb}[25,105,106]$. The ATS recommend FeNO thresholds of $25-50 \mathrm{ppb}$ in adults and 20-35 ppb in children, and the results should to be interpreted with caution and with reference to the clinical context [25].

Fractional exhaled nitric oxide can be used to diagnose steroid-responsive disease and guide asthma management in routine care $[95,99]$. FeNO can also be used to stratify patients who are more likely to respond to interleukin monoclonal antibodies. Patients with an FeNO level $\geq 50 \mathrm{ppb}$ have been shown to have a positive response to mepolizumab [105], and to benralizumab [85].

Fractional exhaled nitric oxide is a useful surrogate biomarker of eosinophilic airway inflammation and offers the advantage of being non-invasive and easy to obtain. The National Institute for Health and Care Excellence [107], and the British Thoracic Society [108], recommend FeNO measurements to guide diagnosis and treatment of eosinophilic asthma. In the UK primary care practices, FeNO monitoring is being used to guide decision on ICS usage or step-up therapy [67]. In addition, the 2019 Global Initiative for Asthma strategy report, recommends the use of FeNO and/or blood eosinophil count to determine the phenotype of asthma, and for selection of biologics for personalized guided treatment [109]. Thus, composite, non-invasive biomarkers, such as FeNO and easily obtainable blood eosinophil count may provide insight into a patient's risk of exacerbations as well as guide asthma treatment $[67,109]$.

\section{Serum Periostin}

Periostin, also termed as osteoblast-specific factor 2, is an extracellular matrix (ECM) protein belonging to the fascilin 1 family [110-113], with a molecular weight of about $90-\mathrm{kDa}[111,114]$. Periostin acts as a matrix protein involved in cell activation by binding to its specific receptors, and several integrins (av $\beta 3$, av $\beta 5, a 4 \beta 6$, and aM $\beta 2)[115,116]$, which are promigratory periostin receptors [116]. Periostin has been implicated in many multisystem diseases [114,117-120], and cancer [121,122].

Perositin secretion is stimulated by IL-13, and IL-4, and plays an important role in the pathogenesis of allergic inflammation, especially Th2-driven eosinophilic asthma $[112,113,115]$. Expression of POSTN, the gene that encodes human periostin is inducible by transforming growth factor (TGF)- $\beta$, IL-13, and IL-4 [123]. The periostin gene, together with CLCA1 (chloride channel regulator) and serpinB2, are highly differentially expressed in the bronchial epithelial cells of patients with asthma [124]. Similarly, Woodruff et al. [125], noted that, the gene expression for periostin is highly expressed in bronchial tissues of patients with asthma. 
Periostin is mainly produced from the basolateral membranes of airway epithelial cells [123], and to a lesser extent from the lung fibroblasts $[113,115,123]$. In patients with asthma, periostin has been shown to be involved in eosinophil recruitment $[126,127]$, goblet cell metaplasia and mucus secretion [128]. Periostin also contributes to increased airway inflammation and hyperresposiveness [130], and leads to an accelerated decline in pulmonary function, despite taking high-dose ICS [131-133].

Periostin deposition in the airways is responsible for airway remodeling and potentially changes the biomechanical properties of the airway [134]. Kanemitsu et al. [132], in a 20 year follow-up study, have shown that periostin deposition in the airway subepithelium of patient with asthma was associated with a decline in lung function (low FEV1) over 20 year. It has been suggested that periostin is responsible for collagen deposition in the subepithelial membrane, leading to subepithelial fibrosis, and the response is IL-13, and IL-4 cytokine-dependent [135]. Similarly, Izuhara and colleagues [136], have reported that increase in periostin deposition leads to thickening of the basement membrane. This is due to localization of perisotin with other ECM proteins, such as collagen I, III and V and tenascin, which may lead to production of subepithelial fibrosis in patients with eosinophilic asthma [136].

Several studies have repoted high serum levels of periostin in patients with eosinophilic asthma compared to control subjects $[24,25,27,123,124]$, Serum periostin levels have been suggested as surrogate markers of Th2-driven eosinophilic airway inflammation [24-28,127,136]. In the BOBCA study of several biomarker in eosinophilic asthma, Jia et al. [27], reported that, periostin was the best predictor of airway eosinophilia in patients with severe asthma that was uncontrolled despite maximal ICS treatment. Furthermore, several studies have recommended serum periostin concentration as a pharmacodynamics biomarker of eosinophilic asthma [59,136-138]. Serum periostin levels show good correlations with blood or sputum eosinophilia [138], and with FENO, and it can be used as a composite marker to identify severe/steroid-insensitive asthma [139].

Serum periostin levels can be used to stratify patients into different phenotypes of asthma who can respond to the personalized targeted biotherapetics [140-142]. Serum perisostin levels were able to stratify patients who could respond to lebrikizumab an IgG4 humanized monoclonal antibody that specifically binds to IL-13 and prevents IL-13-induced heterodimerization with is receptor complex (IL-4Ra/IL-13R 1 and signaling [141,142]. Similarly, it has been shown that serum periostin is a predictive biomarker of response to omalizumab, a recombinant humanized antibody that selectively bind to free IgE [143].

\section{Serum Dipeptidyl Peptidase-4}

Dipeptidyl peptidase-4 (DPP-4) also known as cluster of differentiation 26 (CD26) is a glycoprotein with a molecular weight of about $110-\mathrm{kDa}$ and composed of 766 amino acid residues [144,145]. It is present on the surface of cell membranes and expessed in many tissues, and in peripheral blood as a soluble protein [144,145]. It is mainly present in endothelial cells, submucosal glands, lung epithelial cell, and T cells [146]. Dipeptidyl peptidase-4 expression is increased in airways of patients with asthma, and other diseases with type 2 inflammation, including atopic dermatitis and chronic rhinosinusitis with nasal polyps [147]. DPP-4 has been shown to be a stimulator of proliferation of bronchial smooth muscle cells (BSMCs) [148,149], and human fetal lung fibroblasts, and it promotes the production of fibronectin [149]. DPP-4 mRNA expression can be induced in vitro by IL-13 stimulation of human bronchial epithelial cell from asthmatic patients, and in cultured BSMCs [149]. Elevated membrane DPP-4 expression has also been observed on T lymphocytes from asthmatic patients [150].

Upregulation of DPP-4 may regulate immunological pathway implicated in asthma by inactivating chemokines and growth factors involved in the pathogenesis of asthma [151]. Similar to periostin, DPP-4 is induced by IL-13 and other profibrotic agents, and can be measured in serum, making it a potential biomarker to guide IL-13 mAb therapy in patients with eosinophilic asthma [147,152]. Brightling et al. [153], in phase $2 \mathrm{~b}$ tralokinumab clinical trial, have reported that increased serum DPP-4 levels predict a beneficial response to tralokinumab, an anti-IL-13 mAb, in terms of alleviating symptoms, reducing exacerbations, and improving pulmonary function. However, James et al. [154], have shown that serum DPP-4 levels did not correlate with FEV1, FeNO, blood or sputum eosinonils or IgE in asthmatic patients from the U-BIOPRED and BIOAIR studies. This may indicate that periostin is associated with other Th2 pathways in the pathogenesis of eosinophilic asthma.Streicher et al. [155], have provided a method of treating IL-13 mediated diseases or disorders comprising administration of anti-IL-13 antagonists. They recommend initiation of anti-IL-13 biologics in patients whose blood DPP-4 is above threshold ( $>250 \mathrm{ng} / \mathrm{ml}$ ) in patients with eosinophilic asthma, and other IL-13 mediated diseases [155]. There is also evidence that DPP-4 may serve as a biomarker for aspirin-exacerbated respiratory disease [156].

The potential of DPP-4 in the pathogenesis of eosinophilic asthma is of clinical importance because of the increasing use of DPP-4 inhibitors in the management of patients with type 2 diabetes mellitus, some of whom may have concomitant asthma.Colice et al. [157], reported that there was no difference in asthma control between asthmatic patients initiated on DPP-4 inhibitors and patient not on the inhibitors. This is at the moment good news for eosinophilic asthmatic patientswho have also type 2 diabetes mellitus on DPP-4 inhibitors.

DPP-4 has a broad spectrum of biological functions, such as immune regulation, inflammation and infection, glucose homeostasis, cardiovascular functions, and cancer biology. Recently, DDP-4 has been identified as a serum biomarker for colorectal cancer detection and as a prognostic marker for the cancer [158,159], DPP-4 is also anovel potential diagnostic marker for gastric cancer [160]. 


\section{Treatment}

The goals of asthma treatment is to achieve disease control. Poor control is linked with recurrent asthma attacks which is associated with poor future control [161]. It has become part of clinical practice to manage patients with severe refractory asthma according to established guidelines, such as the BTS/SIGN guidelines [108,109], or the ERS/ATS guidelines [12]. Drugs for the standard management of patients with asthma are listed in Table 3. Patients with uncontrolled asthma should have their treatment intensified by escalating up the treatment steps until control is achieved for at least 3 months $[108,162]$.

\begin{tabular}{|c|}
\hline Inhaled $\beta 2$-agonist \\
\hline Short acting (salbutamol, levalbuterol, terbutaline, pirbuterol) \\
\hline Long-acting (salmeterol, formeterol) \\
\hline Combination of LABA and inhaled corticosteroids \\
\hline Salmetrol and fluticasone (Advair Diskus) \\
\hline Formetorol and budesonide (Symbicort) \\
\hline Cromones \\
\hline Cromlyn sodium, nedocromil sodium \\
\hline Inhaled anti-cholinergics \\
\hline Short-acting (ipratropium bromide) \\
\hline Long-acting (oxitropium bromide, tiotropium bromide) \\
\hline New long-acting (aclidium bromide, glycoprronium) \\
\hline Corticosteroids \\
\hline Betamethasone dipropionate \\
\hline Budenoside, fluticasone, flunisolone, HFA- flunisolide \\
\hline Ciclesonide, mometasone \\
\hline Oral methylxanthines \\
\hline Rapid release theophyllines \\
\hline Sustained release theophyllines (Theo-24, Theocron, Uniphyl) \\
\hline Long-acting PDE-4 inhibitor (Roflumilast) \\
\hline Intravenous theophylline (Aminophylline) \\
\hline Leukotriene receptor antagonists \\
\hline Montelukast, pranlukast \\
\hline Cinalukast, zafirlukast \\
\hline 5-lipoxygenase inhibitors \\
\hline Zileuton \\
\hline
\end{tabular}

Table 3: Drugs for standard treatment of asthma

Corticosteroids are the mainstay therapy for patient with severe, recurrent disease [163]. However, about $10-20 \%$ of the patients remain uncontrolled despite high doses of inhaled corticosteroids (ICSs) up to $2000 \mu \mathrm{g} / \mathrm{day}$, and require the use of chronic oral corticosteroids (OCSs) [12]. It is important to try to achieve control by tailoring the dosage of oral steroids to avoid steroidassociated adverse effects. High dose OCSs or ICSs may be associated with systemic side-effects such as skin thinning, ecchymosis, reduced bone mineral density, cataract, glaucoma and adrenal insufficiency $[48,49]$.

Patients with severe eosinophilic asthma or corticosteroid-refractory asthma, may not achieve control even with high-intensity treatment with ICSs and/or daily OCSs combined with long-acting $\beta 2$-agonists or any other controller medication [54]. They require innovative additional or alternative therapeutic agents in order to achieve disease control [53-55]. The underlying pathophysiology of eosinophilic asthma is airway inflammation and hyperresponsiveness due to inflammatory mediators release by activated Th2 lymphocytes, ILC2s, mast cells, dendritic cells, and eosinophils. The best strategy for the treatment of eosisophilic asthma is to suppress the production, proliferation, differentiation and activation of eosinophils, which play a pivotal role in the airway inflammatory process [164]. Th2 interleukins, particularly, IL-5, IL-4, IL-13, IL-33, and TSLP play an important role in fostering eosinophilic function and survival, and in eosinophilic airway inflammation. Another strategic approach to treat eosinophilic asthma is to block the interleukins and their receptors, which propagate eosinophilic airway responses [51-55].

During the past two decades, alternative biotherapeutic agents have been developed which are particularly targeted and tailored for the treatment of eosinophilic asthma [52-57,165]. They include monoclonal antibodies against IgE, interleukin mABs, and interleukin receptor(ILR) mAbs. Table 4 shows the list of some of the interleukin mAbs and ILR mAbs currently available, and in clinical trials for the treatment of eosinophilic asthma, and corticosteroid-refractory asthma. 


\begin{tabular}{|c|c|c|}
\hline Agent & Target & Stage of Development \\
\hline Omalizumab & IgE & Marketed 2003 \\
\hline Mepolizumab & IL-5 & Marketed 2015 \\
\hline Reslizumab & IL-5 & Marketed 2016 \\
\hline Benralizumab & IL-5R & Marketed 2017 \\
\hline Dupilumab & IL-4a (IL-4/IL-13) & Marketed 2018 \\
\hline Tezepelumab & TSLP & Marketed 2018 \\
\hline Pitrakinra & IL-4a (IL-4/IL-13) & II \\
\hline Lebrikizumab & IL-13 & III \\
\hline Tralokinumab & IL-13 & III \\
\hline Brodalumab & IL-17RA & II \\
\hline Secukinumab & IL-17A & II \\
\hline
\end{tabular}

Table 4: Monoclonal antibodies and interleukin receptor antagonists, and their target

\section{Omalizumab}

Immunoglobulin E plays an important role in the pathophysiology of the allergic inflammation in patients with asthma. Monoclonal antibodies targeted against IgE, such as omalizumab have been shown to attenuate both the early- and late-phase responses to inhaled allergens in patients with asthma [166].

Omalizumab (Xolair ${ }^{\circledast}$ ) was the first monoclonal antibody to be approved by the U. S. Food and Drug Administration (FDA) for the treatment of severe asthma in 2003. Xolair is a recombinant humanized monoclonal antibody to IgE, and is directed against the binding of IgE for its high affinity FceR1 receptor [167]. It binds with the Fc portion of IgE and forms omalizumab:IgE complex. This reduces free IgE and prevents serum IgE from attaching to the FceR1 receptors on mast cells, basophils and eosinophils. This prevents release of inflammatory mediators by these cells. In addition, omalizumab treatment indirectly reduces FceR 1 receptor on cells involved in the allergic responses [167].

Clinical trials using omalizumab treatment in patients with severe eosinophilic asthma have shown reductionin airway and blood eosinophils counts, and reduction in the frequency of exacerbations in patients with eosinophilic asthma [168,169]. Treatment with subcutaneous omalizumab has also been shown to improve asthma control, and improve health-related quality of life (HRQoL). It has also been shown to reduce the need for rescue medication, allow patients to reduce or discontinue their ICS and/or OCSs [168,169].

Xolair is given subcutaneously every two or four weeks depending on the patient's allergy status and body weight. It has an excellent safety profile. Patients need to be monitored for severe allergic reactions after the injection at a medical centre where health care professionals are available to treat the adverse reactions. It is safe and well tolerated. The most common side effects include injection site reaction, respiratory tract infection, pharyngitis, sinusitis, arthralgia, myalgia, muscle weakness, headache, and rarely anaphylaxis. Unfortunately, some patients with eosinophilic asthma do not get symptom relief with the addition of omalizumab to their treatment regimen, and may require an add-on treatment with another biologic, which target other airway inflammatory pathways.

\section{Mepolizumab}

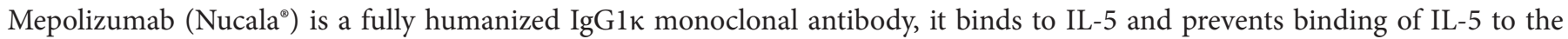
a-chain of the IL-5 receptor complex expressed on the eosinophil cell membrane [170]. This results in inhibition of IL-5 signaling and reducing production, differentiation, activation and survival of eosinophils. Mepolizumab also selectively inhibit eosinophilic inflammation by preventing release of inflammatory mediators from the eosinophils. It was the first anti-IL-5 therapy to be tested in a clinical trial in 2000 [171]. The first clinical trial of mepolizumab in patients with asthma showed a reduction in sputum and blood eosinophil count but no change in bronchial hyperresponsiveness, and no effect on the late asthmatic response. Subsequent clinical trials, including the DREAM study, in patients with eosinophilic asthma and severe exacerbation showed that treatment with mepolizumab resulted in reduction in exacerbation rates, and improvement in asthma symptom questionnaire (ACQ) scores, and the asthma quality of life questionnaire (AQLQ) scores [172]. In the MENSA study, Pavord and colleagues [173], showed that treatment with intravenous (IV) or subcutaneous (SC) mepolizumab decreased the rate of exacerbations by $47 \%$ and $53 \%$ respectively, and reduced exacerbations requiring emergency room visits or hospitalization by $32 \%$ for IV and $61 \%$ for SC mepolizumab. In addition, patients in both IV and SC mepolizumab groups showed significant improvement the FEV1, quality of life, and asthma control as assessed by the St. George's Respiratory Questionnaire (SGRQ) and the ACQ-5. The SIRUS study in patients with severe asthma and peripheral blood eosinophilia while on maintenance corticosteroid revealed that, patients on mepolizumab had a likelihood of reducing corticosteroid-dose 2.37 times greater than patients on placebo [174]. Patients on mepolizumab were also to reduce the corticosteroid dose by $50 \%$, and had lower exacerbation rates and improved asthma control despite receiving lower doses of ICSs or OCSs, thus demonstrating a steroid-sparing effect [174]. In summary, treatment with mepolizumab has been shown to improve the ACQ scores, SGRQ scores, FEV1, reduce the rate of exacerbations, and reduce the 
dosage of corticosteroid or use of other drug modifiers [80,172-174]. Mepolizumab was approved by the FDA in March 2015 for the treatment of eosinophilic asthma. It is recommended at a dosage of $100 \mathrm{mg}$ administered subcutaneously every 4 weeks. It is well tolerated and it has been found to be safe [172]. The most common adverse effects with Nucala are: injection site reaction, headache, backache, fatigue, and muscle weakness. Acute and delayed systemic reactions, including anaphylaxis, urticarial, rash, angioedema, bronchospasm and hypotension may also occur, but they are rare. Patients need to be monitored after treatment for these adverse effects. Eosinophils play an important role in protection against parasitic infection, including helminth infestation. Patients with pre-existing helminth infections should be treated for the infection before mepolizumab therapy. If individuals become infected whilst receiving treatment with Nucala and do not respond to anti-helminth treatment, temporary discontinuation of mepolizumab should be considered.

\section{Reslizumab}

Reslizumab (Cinqair ${ }^{\circledast}$ ) was approved by the FDA on March 23, 2016 as an add-on maintenance therapy in adult patients with severe asthma. It is a humanized monoclonal antibody that target IL-5. The monoclonal antibody has an ERRR configuration (glutamine, arginine, arginine, arginine) corresponding to amino acids 89-92 on the IL-5 antibody molecule. This region is critical for its interaction with the IL-5 receptor which results into inhibition of its bioactivity [175]. Clinical trials with reslizumab have shown significant decrease in sputum eosinophil count, and to improve asthma control questionnaire scores [176]. In the subsequent studies, reslizumab treatment has been shown to improve the FEV1 as early as 4 weeks after initiating therapy [177,178]. It also resulted in larger reductions in exacerbation rates, especially in patients who had repeated exacerbations 12 months prior to the initiation of therapy. The treatment also reduced the use of rescue inhalers. Bjermer and associates [179], have shown that treatment with reslizumab resulted in significant increase in pulmonary function, improvement in self-reported asthma control, and quality of life.

The approved dosage for reslizumab is $3 \mathrm{mg} / \mathrm{kg}$ intravenously over 20-50 minutes every 4 weeks for patients 18 years and above [180]. It is safe and well tolerated by the patients. The most common side effects of Cinqair include headache, nasopharyngitis, myalgia, and fatigue. Anaphylaxis occurs in about $0.3 \%$ of the patients [72], and the U.S. Food and Drug Administration recommends that patients should be observed in a setting where health care professionals are available to treat the adverse reactions. Eosinophils play an important in combating helminth infections. The advice from the manufacturer is that, treat patients with pre-existing helminth infections before initiating Cinqair. If patients become infected while receiving treatment with reslizumab and do not respond to anti-helminth treatment, discontinue treatment with reslizumab until infection resolves.

\section{Benralizumab}

Benralizumab (Fasenra ${ }^{\mathrm{TM}}$ ) is a fully humanized $\mathrm{IgG} 1 \mathrm{~K}$ afucosylated monoclonal antibody to a subunit of the IL-5 receptor on eosinophils. Antibody binding uniquely leads to attraction of natural killer cells and apoptosis of these cells through cell-mediated cytotoxiciy, and dramatically reduces their numbers and eosinophilic inflammation. Preliminary studies have shown that treatment with benralizumab resulted in a decrease in blood eosinophil count to almost depletion, reduction in the rate of exacerbations, and improvement in the ACQ-5 scores [181,182]. The SIROCCO study showed that treatment with benralizumab significantly reduced exacerbation rates, and improve lung function, and asthma control in patients with severe asthma uncontrolled on high-dose inhaled corticosteroids and long-acting $\beta$-agonists [183]. Fitzgerald and colleagues in the CALIMA study, and thepooled analysis of the SIROCCO and CALIMA studies, reveled that treatment with subcutaneous benralizumab 30 mg every 4 weeks resulted in a $36 \%$ reduction in exacerbations, and a significant increase of $125 \mathrm{ml}$ in FEV1 [184,185]. In the Phase III oral corticosteroidsparing trial, ZONDA, benralizumab treatment resulted in up to $51 \%$ reduction in annual asthma exacerbation rate (AAER) versus placebo. There was also a significant improvement in lung function as measured by FEV1. The FEV1 increased by 159 ml, and the improvement in lung function was seen as early as 4 weeks after the initiation of the treatment [184]. Noteworthy, there was a 75\% median reduction in daily OCS use and discontinuation in 52\% of the eligible patients [186].

Fasenra was approved by the U.S. Food and Drug Administration on November 14, 2017, as add-on therapy for people with severe eosinophilic asthma aged 12 years and older, and those whose asthma is not controlled with current asthma medication. Benralizumab is available as a single-dose pre-filled syringe. The recommended dose is $30 \mathrm{mg} / \mathrm{ml}$ injection subcutaneously every 4 weeks for the first three doses then every eight weeks. It is well tolerated with adequate safety profile [184]. The most common adverse effects of Fasenra include headache (8.6\%), pharyngitis (4\%), arthralgia (3.9\%, cough (3.3\%), injection site reaction (2.2\%), and urticaria rash. It is not known if Benralizumab will influence helmith infestation or response to anti-helminth treatment. The manufacturers recommend treatment of the parasitosis before initiating Fasenra, and if patients become infected while receiving Fasenra and do not respond to anti-parasitic agents, to discontinue benralizumab until the infection resolves.

\section{Dupilumab}

Dupilumab (Dupixent ${ }^{\circledR}$ ) is a fully humanized IgG4 monoclonal antibody to the IL-4 receptor. The IL-4 receptor is composed of the IL-4R $a$ chain and the IL-13R 1 chain and mediate signaling to both IL-4 and IL-13 [187]. Dupixent inhibits both IL-4 and IL-13 receptor subunits [187]. IL-4 and IL-13 are key cytokines that contribute to the Th2-driven eosinophilic inflammation that 
lead to moderate-to-severe asthma. In the clinical trials, treatment with dupilumab administration subcutaneously was associated with reduction in inflammatory biomarkers including fraction exhaled nitric oxide (FeNO), serum immunoglobulin E (IgE), and eotaxin-3 (CCL26) [188]. Dupixent has been shown to significantly reduce severe exacerbations by $67 \%$, improve lung function (FEV1) by 29\%-33\%, reduce morning and evening symptoms, and improve asthma control in patients with moderate-to-severe eosinophilic asthma. The FEV1 was improved after 2 weeks of treatment and was maintained through week 12, despite the patients not taking LABA and inhaled corticortisteroids [189]. In Phase $2 \mathrm{~b}$ trial, dupilumab administration subcutaneously demonstrated a reduction in the daily use of oral corticosteroids by $70 \%$ compared $42 \%$ with placebo. More than half of the patients treated with the drug completely eliminated the use of oral corticosteroids [190]. Dupilumab was approved by the Committee for Medicinal Products for Human Use of the European Medicines Agent (EMA) on October 19, 2018, at 5.55 PM, as an add-on maintenance therapy in patients with moderate-to-severe asthma, and eosinophilic asthma aged 12 years and older. It is also approved by the U.S. Food and Drug administration, and for patients with oral corticosteroid-dependent asthma. Dupixent is available as a singledose pre-filled syringe and is administered subcutaneously under the guidance of a healthcare provider. It comes in two doses (200 $\mathrm{mg}$ and $300 \mathrm{mg}$ ) given on alternative weeks at different injection sites after an initial loading dose.

On the other hand, dupilumab treatment results in significant improvement in disease activity,and improves general healthrelated quality-of-life in adults with moderate to severe atopic dermatitis [191]. It is approved by the FDA for the treatment of adults with moderate-to-severe atopic dermatitis. The most common adverse effects of dupilumab include injection site reaction, upper respiratory tract infection, nasopharyngitis, pruritus, herpes labialis, and other herpes simples infection, eye and eyelid inflammation, conjunctivitis, keratitis, and rarely anaphylaxis. Patients should be observed after the treatment in a setting where health care professionals are available to treat the adverse reactions. It is not known if dupilumab will influence the immune response against helminth infection. Treat patients with pre-existing helminth infections before commencing Dupixent. If patients become infected while receiving while receiving dupilumab and do not respond to anti-helminth treatment discontinue treatment with dupilumab until the parasitosis resolves.

\section{Tralokinumab}

Interleukin-13 signaling plays an important role in the pathogenesis of asthma, and pharmacological agents have been developed to target its activities. The IL-13 receptor is a complex assembly of both IL-4 and IL-13 receptor subunits. Tralokinumab is a humanized IgG4 monoclonal antibody to IL-13, it is currently in phase III clinical trials. In the STRATOS 1 clinical study, which enrolled 1202 patients with uncontrolled asthma, tralokimumab $300 \mathrm{mg}$ administered subcutaneously reduced annual asthma exacerbation rates in participants with an FeNO higher than 37 ppm. However, in the STRATOS 2 clinical trial which enrolled

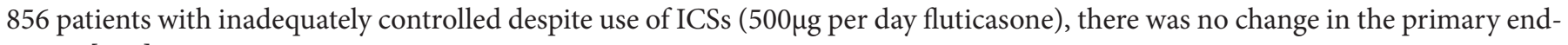
points [192].

On the happy note, tralokinumab induces significant clinical improvement in moderate-to-severe atopic dermatitis [193]. It is expected to compete very effectively with Dupixent in the treatment of atopic eczema, which is a common comorbid disease with eosinophilic asthma.

\section{Lebrikizumab}

Lebrikizumab is a humanized IgG4 monoclonal antibody that binds to IL-13 and blocks its action. In the LAVOLTA I and LAVOLTA II studies which enrolled 1081 and 1067 patients respectively with poorly uncontrolled asthma, treatment with lebrikizumab 37.5 $\mathrm{mg}$ and $125 \mathrm{mg}$ subcutaneous injection significantly reduced exacerbation rates in patients with high perostin levels (> 50 ng/ $\mathrm{ml}$ ), but not in patients with normal or low periostin levels [194]. However, pooled data did not consistently show significant reduction in asthma exacerbation rates in biomarker-high patients, and clinically relevant changes could not be ruled out.194 Periostin is a downstream IL-13-induced protein derived from the airway epithelial cells, and it may be useful in monitoring patients with eosinophilic asthma. Probably, lebrikizumab may be suitable in some patients with severe eosinophilic asthma with elevated periostin levels.

\section{Tezepelumab}

Tezepelumab is a first-in-class human anti-thymic stomal lymphopoietin mAb, which inhibits the inflammatory activity of TSLP. Blocking TSLP may prevent release of pro-inflammatory cytokines including IL4, IL-5, IL-13, and IL-33 from Th2 cells, ILC2s, mast cells, dendritic cells, basophils, and eosinophils, and attenuate the inflammation process. Due to its multiple pathways in the inflammatory cascade, tezepelumab may be suitable for a broad population of patients with severe uncontrolled asthma irrespective of patient phenotype or Th2 biomarker status [195]. In PATHWAY Phase $2 \mathrm{~b}$ clinical trial, tezepelumab given every four weeks subcutaneously at doses of $70 \mathrm{mg}$ (low), $210 \mathrm{mg}$ (medium); and $280 \mathrm{mg}$ (high) every two weeks, was shown to result in significant improvement in Asthma Control Questionnaire-6 (ACQ-6) scores, and AQLQ scores at medium and high dosages [196]. It was also shown to reduce asthma exacerbations by $62 \%$, compared to placebo, and improvement in prebronchodilator FEV1 [196]. These effects were observed independent of baseline eosinophil count or other Th2 inflammatory biomarkers. It was approved by the U.S. Food and Drug Administration on September 7, 2018 at 02.00 ET, for the treatment of moderate-to-severe uncontrolled asthma in adults. The common adverse events of tezepelumab, include nasopharyngitis, bronchitis, and headache. 


\section{Other Biological Agents}

There are several biologics currently in clinical trial targeting the broad range of interleukins and other cytokines, such as pitrakinra, brodalumab (Siliq), and secukinumab (Cosentyx). Brodalumab is an IL-1RA mAb, and seculimub is an IL-17 mAb, both are targeted at IL-17 a signature cytokine for neutrophilic asthma [197-199]. Siliq and cosentyx have only been approved for the treatment of plaque psoriasis [200,201]. Additionally, secukinumab is a preferred treatment for patients with comorbid psoriatic arthritis or arthralgia symptoms, due to its ability to inhibit progression of arthritic disease [200].

When initiating targeted biologics for patients with clinically established esinophilic asthma, it important to start the treatment before the disease becomes chronic with fixed airflow limitation. The GINA [202], and British Thoracic Society, Scottish Intercollegiate [203], guidelines recommend initiation of anti-IgE at step 5, whereas the Expert Panel Report 3 (EPR 3 ) guidelines recommends add-on treatment with anti-IgE biologics at step 5 and 6 [204]. Patients who should be recommended to use the novel biologics at an earlier step include patients with biomarker documented eosinophilic asthma, and any other patient with severe asthma or recurrent exacerbations. Another group of patients who are likely to benefit from mAbs and ILRAs therapy include patients with corticosteroid-refractory asthma, and those with chronic rhinosinusitis and nasal polyps. Early use of these agents might avoid the usage of large doses of oral corticosteroids, and reduce the serious adverse effects due to corticosteroids.

\section{Conclusion}

Asthma is a complex heterogenous chronic airway disease characterized by airway inflammation, hyperresponsiveness, and airway remodeling. There are several different phenotypes of asthma which include eosinophilic asthma. Eosinophilic asthma is a very severe refractory disease with recurrent exacerbations, poor quality of life, and has a worse prognosis. It is difficult to treat with the current stepwise therapy including oral corticosteroids. Alternative tailored treatment for this subgroup of patients include blockade of the cytokine inflammatory mediators such as IL-5, IL4, IL-13, IL-33, and TSLP, which orchestrate and perpetuate the inflammatory response. Biomarkers such as sputum and blood eosinophil counts, FeNO, serum periostin and DPP-4 levels are very useful in stratifying the phenotypes of asthma for targeted personalized treatment with biologics. The newly introduced biotherapeutics for the treatment of eosinophilic asthma include IgE monoclonal antibodies, e.g. omalizumab, and interleukin and interleukin receptor antagonists such as mepolizmab, benrlizumab, dupilumab and reslizumab. These agents have been shown to improve the asthma control questionnaire scores, reduced the rate of exacerbations, improve pulmonary function, and the quality of life. They also reduce the dose or the need for ICSs or OCSs when used as an add-on treatment in patients with eosinophilic asthma.

\section{Conflicts of interest}

The author reports no conflicts of interest in this manuscript.

\section{References}

1. Wenzel SE (2005) Asthma: defining of the persistent adult phssenotypes. Lancet 368: 804-13.

2. Wenzel SE, Busse WW (2007) Severe asthma: lessons from the Severe Asthma Research Program. J Allergy Clin Immunol 119: 14-21.

3.Wenzel SE, Schwartz LB, Langmack EL, Halliday JL, Trudeau JB, et.al. (1999) Evidence that severe asthma can be divided pathologically into two inflammatory subtypes with distinct physiologic and clinical characteristics. Am J Respir Crit Care Med 160: 1001-8.

4. Bel EH, Souza A, Fleming L (2011) Diagnosis and definition of severe refractory asthma: an international consensus statement from the Innovative Medicine Initiative (IMI). Thorax 66: 910-17.

5. Wenzel SE (2012) Asthma phenotypes: the evolution from clinical to molecular approaches. Nat Med 18: 716-25.

6. Pavord ID (2013) Eosinophilic phenotypes of airway disease. Ann Am Thorac Soc 10: S143-9.

7. Buhl R, Humbert M, Bjermer L, Chanez P, Heaney LG, et.al. (2007)Severe eosinophilic asthma: a roadmap to consensus.Eur Respir J 49: 1700634.

8. Miranda C, Busacker A, Balzar S, Trudeau J, Wenzel SE (2004)Distinguishing severe asthma phenotypes: role of age at onset and eosinophilic inflammation. J Allergy Clin Immunol 113: 101-8.

9. Haldar P, Pavord ID, Shaw DE, Berry MA, Thomas M, et.al. (2008) Cluster analysis and clinical asthma phenotypes.Am J Respir Crit Care Med 178: 218-24.

10. de Groot JC, Ten Brinke A, Bel EH (2015) Management of the patient with eosinophilic asthma: a new era begins. ERJ Open Res 1: 00024-2015.

11. Wenzel SE, Fahy J, Irvin C, Peters S, Spector S, et.al. (2000). Proceedings of the ATS workshop on refractory asthma: current understanding, recommendations, and unanswered questions. American Thoracic Society. Am J Respir Crit Care Med 162: 2341-51.

12. Chung KF, Wenzel SE, Brozek JL, Bush A, Castro M, et.al. (2014) International ERS/ATS guidelines on definition, evaluation and treatment of severe asthma. Eur Respir J 43: 343-73.

13. Moore WC, Bleecker ER, Curran-Everett D, Erzurum SC, Ameredes BT, et al. (2007) Characterization of the severe asthma phenotype by the National Heart, Lung, and Blood Institute's Severe Asthma Research Program. J Allergy Clin Immunol 119: 405-13.

14. Bartminski G, Crossley M, Turcanu V (2015) Novel biomarkers for asthma stratification and personalized therapy.Expert Rev Mol Diagn 15: 415-30.

15. Ten Brinke A, Zwinderman AH, Sterk PJ, Rabe KF, Bel EH (2014) Factors associated with persistent airflow limitation in severe asthma. Am J Respir Crit Care Med 164: 744-8.

16. Price D, Fletcher M, van der Molen T (2014) Asthma control and management in 8,000 European patients: the REcognise Asthma and LInk to Symptoms and Experience (REALISE) survey. NPJ Prim Care Respir Med 24: 14009.

17. NHS (2011) NHS atlas of variation in healthcare for people with respiratory disease, UK. 
18. O'Neill S, Sweeney J, Patterson CC, Menzies-Gow A, Niven R, et al. (2015) The cost of treating severe refractory asthma in the UK: an economic analysis from the British Thoracic Society Difficult Asthma Registry. Thorax 70: 376-8.

19. Wenzel SE, Schwartz B, Langmack EL, Halliday JL, Trudeau JB, et al. (1999) Evidence that severe asthma can be divided into two inflammatory subtypes with distinct physiologic and clinical characteristics. Am J Respir Crit Care Med 160: 1001-8.

20. Tran TN, Khatry DB, Ke X, Ward CK, Gossage D (2014) High blood eosinophil count is associated with more frequent asthma attacks in asthma patients. Ann Allergy Asthma Immunol 113: 19-24.

21. Nair P(2013) What is an "eosinophilic phenotype" of asthma? J Allergy Clin Immunol 132: 81-3.

22. Burrows B, Martinez FD, Halonen M, Barbee RA, Cline MG (1989) Association of asthma with serum IgE levels and skin-test reactivity to allergens. N Engl J Med 320: 271-7.

23. Platts-Mills TA (2001) The role of immunoglobulin E in allergy and asthma. Am J Respir Crit Care Med 164: S1-5.

24. Kharitonov SA, Yates D, Robbins RA, Logan-Sinclair R, Shinebourne EA, et al. (1994) Increased nitric oxide in exhaled air of asthmatic patients. Lancet 343: $133-5$.

25. Dweik RA, Boggs PB, Erzurum SC, Irvin CG, Leigh MW, et al. (2011)An official ATS clinical practice guideline: interpretation of exhaled nitric oxide levels (FENO) for clinical applications. Am J Respir Crit Care Med 184: 602-15.

26. Jia G, Erickson RW, Choy DF, Mosesova S, Wu LC, et al. (2012) Periostin is a systemic biomarker of eosinophilic airway inflammation in asthmatic patients. J Allergy Clin Immunol 130: 647-54.

27. Jia G, Erickson RW, Choy DF, Mosesova S, Wu LC, et al. (2012) Bronchoscopic Exploration Research Study of Biomarkers in Corticosteroid-refractory Asthma (BOBCA) study Group. Periostin is a systemic biomarker of eosinophilic airway inflammation in asthmatic patients. J Allergy Clin Immunol 130: 647-654.e10.

28. Parulekar AD, Atik MA, Hanania NA (2014) Periostin, a novel biomarker of TH2-driven asthma. Curr Opin Pulm Med 20: 60-5.

29. Busse W, Spector S, Rosén K, Wang Y, Alpan O (2013) High eosinophil count: a potential biomarker for assessing successful omalizumab treatment effects. J Allergy Clin Immunol 132: 485-6.

30. Bel EH, Wenzel SE, Thompson PJ, Prazma CM, Keene ON, et al. (2014) Oral glucocorticoid-sparing effect of mepolizumab in eosinophilic asthma. N Engl J Med 371: 1184-97.

31. Green RH, Brightling CE, McKenna S, Hargadon B, Parker D, et al. (2002) Asthma exacerbations and sputum eosinophil counts: a randomised controlled trial. Lancet 360: 1715-21.

32. Jayaram L, Pizzichini MM, Cook RJ, Boulet LP, Lemière C, et al. (2006) Determining asthma treatment by monitoring sputum cell counts: effect on exacerbations. Eur Respir J 27: 483-94.

33. Kudo Y, Siriwardena BS, Hatano H, Ogawa I, Takata T (2007) Periostin: novel diagnostic and therapeutic target for cancer. Histol Histopathol 22 : 1167-74.

34. Hanania NA, Alpan O, Hamilos DL, Condemi JJ, Reyes-Rivera I, et al. (2011) Omalizumab in severe allergic asthma inadequately controlled with standard therapy: a randomized trial. Ann Intern Med 154: 573-82.

35. Amelink M, de Groot JC, de Nijs SB, Lutter R, Zwinderman AH, et al. (2013) Severe adult-onset asthma: A distinct phenotype. J Allergy Clin Immunol 132: $336-41$

36. de Groot JC, Ten Brinke A, Bel EH (2015) Management of the patient with eosinophilic asthma: a new era begins. ERJ Open Res 1: 00024-2015.

37. Szczeklik A, Stevenson DD (2003) Aspirin-induced asthma: advances in pathogenesis, diagnosis, and management. J Allergy Clin Immunol 111: 913-21.

38. Lunde H, Hedner T, Samuelsson O, Lötvall J, Andrén L, et al. (1994) Dyspnoea, asthma, and bronchospasm in relation to treatment with angiotensin converting enzyme inhibitors. BMJ 308: 18-21

39. Bresciani M, Paradis L, Des Roches A, Vernhet H, Vachier I, et al. (2001) Rhinosinusitis in severe asthma. J Allergy Clin Immunol 107: 73-80.

40. ten Brinke A, Grootendorst DC, Schmidt JT, De Brüne FT, van Buchem MA, et al. (2002) Chronic sinusitis in severe asthma is related to sputum eosinophilia. J Allergy Clin Immunol 109: 621-26.

41. Ehnhage A, Olsson P, Kölbeck KG, Skedinger M, Dahlén B, et al. (2009) Functional endoscopic sinus surgery improved asthma symptoms as well as PEFR and olfaction in patients with nasal polyposis. Allergy 64: 762-9.

42. Kiljander TO, Junghard O, Beckman O, Lind T (2010) Effect of esomeprazole $40 \mathrm{mg}$ once or twice daily on asthma: a randomized, placebo-controlled study. Am J Respir Crit Care Med 181: 1042-8.

43. Shore SA (2008) Obesity and asthma: possible mechanisms. J Allergy Clin Immunol 121: 1087-93.

44. Boulet LP, Turcotte H, Martin J, Poirier P (2012) Effect of bariatric surgery on airway response and lung function in obese subjects with asthma. Respir Med 106: 651-60.

45. Berry MA, Hargadon B, Shelley M, Parker D, Shaw DE, et al. (2006) Evidence of a role of tumor necrosis factor alpha in refractory asthma. N Engl J Med 354: 697-708

46. Flood-Page P, Menzies-Gow A, Phipps S, Ying S, Wangoo A, et al. (2003) Anti-IL-5 treatment reduces deposition of ECM proteins in the bronchial subepithelial basement membrane of mild atopic asthmatics. J Clin Invest 112: 1029-36.

47. Mauad T, Silva LF, Santos MA, Grinberg L, Bernardi FD, et al. (2004) Abnormal alveolar attachments with decreased elastic fiber content in distal lung in fatal asthma. Am J Respir Crit Care Med 170: 857-62.

48. Manson SC, Brown RE, Cerulli A, Vidaurre CF (2009) The cumulative burden of oral corticosteroid side effects and the economic implications of steroid use. Respir Med 103: 975-94.

49. Baptist AP, Reddy RC (2009) Inhaled corticosteroids for asthma: are they safe? J Clin Pharm Ther 34: 1-12.

50. Muñoz X, Bustamante V, Lopez-Campos J, Cruz M.-J, et al. (2015) Usefulness of noninvansive methods for the study of bronchial inflammation in the control of patients with asthma. Int Arch Allergy Immunol 166: 1-12.

51. Bagnasco D, Ferrando M, Varricchi G, Passalacqua G, Canonica GW (2016) A Critical Evaluation of Anti-IL-13 and Anti-IL-4 Strategies in Severe Asthma. Int Arch Allergy Immunol 170: 122-31.

52. Yancey SW, Keene ON, Albers FC, Ortega H, Bates S, et al. (2017) Biomarkers for severe eosinophilic asthma. J Allergy Clin Immunol 140: 1509-18.

53. Busse WW (2019) Biological treatments for severe asthma: A major advance in asthma care. Allergol Int 68: 158-66. 
54. Wan XC, Woodruff PG (2016) Biomarkers in severe asthma. Immunol Allergy North Am 36: 547-57.

55. Schleich F, Demarche S, Louis R (2016) Biomarkers in the management of difficult asthma. Curr Top Med Chem 16: 1561-73.

56. Kim H, Ellis AK, Fischer D, Noseworthy M, Olivenstein R, et al. (2017) Asthma biomarkers in the age of biologics. Allergy Asthma Clin Immunol 13: 48.

57. Tiotiua A (2018) Biomarker in asthma. State of the art. Asthma Res Pract 4: 10.

58. Kupczyk M, ten Brinke A, Sterk PJ, Bel EH, Papi A, et al. (2014) Frequent exacerbators--a distinct phenotype of severe asthma. Clin Exp Allergy 44: $212-21$.

59. Wagener AH, de Nijs SB, Lutter R, Sousa AR, Weersink EJ, et al. (2015) External validation of blood eosinophils, FE(NO) and serum periostin as surrogates for sputum eosinophils in asthma. Thorax 70: 115-20.

60. SimpsoAn JL, Scott R, Boyles MJ, Gibson PG (2006) Inflammatory subtypes in asthma: Assessment and identification using induced sputum. Respirology 11: 54-61. 61. Cowan DC, Taylor DR, Peterson LE, Cowan JO, Palmay R, et al. (2015) Biomarker-based asthma phenotypes of corticosteroid response. J Allergy Clin Immunol 135: 877-83.

62. Medrek SK, Parulekar AD, Hanania NA (2017) Predictive biomarker for asthma therapy. Curr Allergy Asthma Rep.

63. Haldar P, Brightling CE, Hargadon B, Gupta S, Monteiro W, et al. (2009) Mepolizumab and exacerbations of refractory eosinophilic asthma. N Engl J Med 360: 973-84.

64. Busse W, Spector S, Rosén K, Wang Y, Alpan O (2013) High eosinophil count: a potential biomarker for assessing successful omalizumab treatment effects. J Allergy Clin Immunol 132: 485-6.

65. Castro M, Mathur S, Hargreave F, Boulet LP, Xie F, et al. (2011) Reslizumab for poorly controlled, eosinophilic asthma: a randomized, placebo-controlled study. Am J Respir Crit Care Med 184: 1125-32.

66. Wenzel S, Ford L, Pearlman D, Spector S, Sher L, et al. (2013) Dupilumab in persistent asthma with elevated eosinophil levels. N Engl J Med 368: 2455-66. 67. Price DB, Bosnic-Anticevich S, Pavord ID, Roche N, Halpin DMG, et al. (2019) Association of elevated fractional exhaled nitric oxide concentration and blood eosinophil count with severe asthma exacerbations. Clin Transl Allergy 9: 41.

68. Katz LE, Gleich GJ, Hartley BF, Yancey SW, Ortega HG (2014) Blood eosinophil count is a useful biomarker to identify patients with severe eosinophilic asthma. Ann Am Thor Soc 11:531-6.

69. Woodruff PG, Khashayar R, Lazarus SC, Janson S, Avila P, et al. (2001) Relationship between airway inflammation, hyperresponsiveness, and obstruction in asthma. J Allergy Clin Immunol 108: 753-8.

70. Price DB, Rigazio A, Campbell JD, Bleecker ER, Corrigan CJ, et al. (2015) Blood eosinophil count and prospective annual asthma disease burden: a UK cohort study. Lancet Respir Med 3: 849-58.

71. Tran TN, Khatry DB, Ke X, Ward CK, Gossage D (2014) High blood eosinophil count is associated with more frequent asthma attacks in asthma patients. Ann Allergy Asthma Immunol 113: 19-24.

72. Kerkhof M, Tran TN, van den Berge M, Brusselle GG, Gopalan G, et al. (2018) Association between blood eosinophil count and risk of readmission for patients with asthma: historical cohort study. PLoS One 13: e0201143.

73. Hancox RJ, Pavord ID, Sears MR (2018) Associations between blood eosinophils and decline in lung function among adults with and without asthma. Eur Respir J.

74. Nadif R, Siroux V, Oryszczyn MP, Ravault C, Pison C, et al. (2009) Heterogeneity of asthma according to blood inflammatory pattern. Thorax 64: 374-80.

75. Schleich FN, Chevremont A, Paulus V, Henket M, Manise M, et al. (2014) Importance of concomitant local and systemic eosinophilia in uncontrolled asthma. Eur Respir J 44: 97-108.

76. Konradsen JR, Skantz E, Nordlund B, Lidegran M, James A, et al. (2015) Predicting asthma morbidity in children using proposed markers of Th2-type inflammation. Pediatr Allergy Immunol 26: 772-9.

77. Berry A, Busse WW (2016) Biomarkers in asthmatic patients: Has their time come to direct treatment. J Allergy Clin Immunol 137: 1317-24.

78. Fitzpatrick AM (2016) Severe asthma in children: lessons learned and future directions. Allergy Clin Immunol Pract 4: 11-9.

79. Wark PA, McDonald VM, Gibson PG (2015) Adjusting prednisone using blood eosinophils reduces exacerbations and improve asthma control in difficult patients with asthma. Respirology 20: 1282-4.

80. Ortega HG, Yancey SW, Mayer B, Gunsoy NB, Keene ON, et al. (2016) Severe eosinophilic asthma treated with mepolizumab stratified by baseline eosinophil thresholds: a secondary analysis of the DREAM and MENSA studies. Lancet Respir Med 4: 549-56.

81. Bjermer L, Lemiere C, Maspero J, Weiss S, Zangrilli J, et al. (2016) Reslizumab for inadequately controlled asthma with elevated eosinophil levels: a randomized phase 3 study. Chest 150: 789-98.

82. Bleecker ER, FitzGerald JM, Chanez P, Papi A, Weinstein SF, et al. (2016) Efficacy and safety of benralizumab for patients with severe asthma uncontrolled with highdosage inhaled corticosteroids and long-acting $\beta 2$-agonists (SIROCCO): a randomised, multicentre, placebo-controlled phase 3 trial. Lancet 388: 2115-27.

83. Castro M, Corren J, Pavord ID, Maspero J, Wenzel S, et al. (2018) Dupilumab efficacy and safety in moderate-to-severe uncontrolled asthma. N Engl J Med 378: 2486-96. 84. Corren J, Weinstein S, Janka L, Zangrilli J, Garin M (2016) Phase 3 study of reslizumab in patients with poor controlled asthma: effects across a broad range of eosinophil counts. Chest 150: 799-810.

85. Castro M, Wenzel SE, Bleecker ER, Pizzichini E, Kuna P, et al. (2014) Benralizumab, an anti-interleukin 5 receptor a monoclonal antibody, versus placebo for uncontrolled eosinophilic asthma: a phase $2 \mathrm{~b}$ randomised dose-ranging study. Lancet Respir Med 2: 879-90.

86. Korevaar DA, Westerhof GA, Wang J, Cohen JF, Spijker R, et al. (2015) Diagnostic accuracy of minimally invasive markers for detection of airway eosinophilia in asthma: a systemic review and meta-analysis. Lancet Respir Med 3: 290-300.

87. Zhang XY, Simpson JL, Powell H, Yang IA, Upham JW, et al. (2014) Full blood count parameters for the detection of asthma inflammatory phenotypes. Clin Exp Allergy 44: $1137-45$.

88. Westerhof GA, Korevaar DA, Amelink M, de Nijs SB, de Groot JC, et al. (2015) Biomarkers to identify sputum eosinophilia in different asthma phenotypes. Eur Respir J 46: 688-98.

89. Soma T, Iemura H, Naito E, Miyauchi S, Uchida Y, et al. (2018) Implication of fraction of exhaled nitric oxide and blood eosinophil count in severe asthma. Allergol Int 67: S3-S11.

90. Barnes PJ (1996) NO or NO in asthma? Thorax 51: 218-22.

91. Moncada S, Higgs A (1993) The L-arginine-nitric oxide pathway. N Engl J Med 329: 2002-12. 
92. Maarsingh H, Zuidhof AB, Bos IS, van Duin M, Boucher JL, et al. (2008) Arginase inhibition promotes against allergen-induced airway obstruction, hyperresponsiveness, and inflammation. Am J Respir Crit Care Med 178: 565-73.

93. Lane C, Knight D, Burgess S, Franklin P, Horak F, et al. (2004) Epithelial inducible nitric oxide synthase activity is the major determinant of nitric oxide concentration in exhaled breath. Thorax 59: 757-60.

94. Fitzpatric AM (2015) Biomarkers of asthma and allergic diseases. Ann Allergy Asthma Immunol 115: 335-40.

95. Maleba M, Ragnoli B, Raaeli A, Tantucci C (2008) Usefulness of exhaled nitric oxide and sputum eosinophils in the long-term control of eosinophilic asthma. Chest 134: 733-9.

96. Gao J, Wu F (2018) Association between fractional exhaled nitric oxide, sputum induction and peripheral blood eosinophil in uncontrolled asthma. Allergy Asthma Clin Immunol 14: 21.

97. Warke TJ, Fitch PS, Brown V, Taylor R, Lyons JDM, et al. (2002) Exhaled nitric oxide correlates with airway eosinophils in childhood asthma. Thorax 57: 5.

98. Price DB, Buhl R, Chan A, Freeman D, Gardener E, et al. (2018) Fractional exhaled nitic oxide as a predictor to inhaled corticosteroids in patients with nonspecific respiratory symptoms and insignificant bronchodilator reversibility: a randomized controlled trial. Lancet Respir Med 6: 29-39.

99. Price D, Ryan D, Burden A, Ziegenweidt JV, Gould S, et al. (2013) Using fractional exhaled nitric oxide (FeNO) to diagnose steroid-responsive disease and guide asthma management in routine care. Clin Transl Allergy 3: 37.

100. Dupont LJ, Rochette F, Demedts MG, Verleden GM (1998) Exhaled nitric oxide correlates with airway hyperresponsiveness in steroid-naïve patients with mild asthma. Am J Respir Crit Care Med 157: 894-8.

101.Gelb AF, Flynn Taylor C, Shinar CM, Gutierrez C, Zamel N (2006) Role of spirometry and exhaled nitric oxide to predict exacerbations in treated asthmatics. Chest 129: 1492-9.

102. Zeiger RS, Schatz M, Zhang F, Crawford WW, Kaplan MS, et al. (2011) Elevated exhaled nitric oxide is a clinical indicator of future uncontrolled asthma in asthmatic patients on inhaled corticosteroids. J Allergy Clin Immunol 128: 412-4.

103. Malinovschi A, Fonseca JA, Jacinto T, Alving K, Janson C (2013) Exhaled nitric oxide levels and blood eosinophil counts independently associate with wheeze and asthma in National Health and Nutrition Examination Survey subjects. J Allergy Clin Immunol 132: 821-7.

104. Optimum Patient Care (2019) Anonymised Data Ethics \& Protocol Transparency (ADEPT) committee, UK.

105. Pavord ID, Korn S, Howarth P, Bleecker ER, Buhl IR, et al. (2012) Mepolizumab for severe eosonophilic asthma (DREAM): a multicenter, double-blind, placebo-controlled trial. The Lancet 80: 651-9.

106. Sandrini A, Taylor DR, Thomas PS, Yates DH (2010) Fractional exhaled nitric oxide in asthma: an update. Respirology 15: 57-70.

107. National Institute for Health and Care Excellence (NICE) (2017) Asthma: diagnosis, monitoring and chronic asthma management, NICE, UK.

108. British Thoracic Society, Scottish Intercollegiate Network (2016) BTS/SIGN British guidelines on the management of asthma. BTS/SIGN, UK.

109. Global Initiative for Asthma (GINA) (2019) Global strategy for asthma management and prevention.GINA.

110. Takeshita S, Kikumo R, Tezuka K, Amann E (1993) Osteoblast factor-2: cloning of a putative bone adhesion protein with homology with insect protein fasciclin 1. Bioch J 294: 27-8

111. Conway SJ, Izuhara K, Kudo Y, Litvin J, Markwald R, et al. (2014) The role of periostin in tissue remodeling across health and disease. Cell Mol Life Sci 71: 1279-88.

112. Izuhara K, Arima K, Ohta S, Suzuki D, Inamitsu M, et al. (2014) Periostin in allergic inflammation. Allergol Int 63: 143-51.

113. Izuhara K, Matsumoto H, Ohta S, Ono J, Arima K (2015) Recent developments regarding periostin in bronchial asthma. Allergol Int 64: S3-S10.

114. Morra L, Reschsteiner M, Casagrande S, von Teichman A, Schraml (2012) Characteristerization of periostin isoform pattern in non-small cell lung cancer. Lung Cancer 79: 183-90

115. Izuhara K, Conway S, Moore BB, Matsumoto H, Holweg CTJ (2016) Role of periostin in respiratory disorders. Am J Respir Crit Care Med 193: 9.

116. Johansson MW, Annis DS, Mosher DF (2013) aM $\beta 2$ integrin-mediated adhesion and motility of IL5 stimulated eosinophils on periostin. Am J Respir Cell Mol Biol 48: 503-10.

117. Mael-Ainin M, Abed A, Conway SJ, Dussaule JC, Chatziantoniou C (2014) Inhibition of periostin expression protects against the development of renal inflammation and fibrosis. J Am Soc Nephrol 25: 1724-36

118. Arima K, Ohta S, Tagaki A, Shiraishi H, Masuoka M, et al. (2015) Periostin contributes to epidermal hyperplasia in psoriasis common to atopic dermatitis. Allergol Int 64: 41-8.

119. Huang Y, Yiu W, Xiao H, Maitikabili A, Lin Q, et al. (2015) Maricellular periostin contributes to hepatic inflammation and fibrosis. Am J Pathol 185: 786-97.

120. Uchida M, Shiraishi H, Ohta S, Arima K, Taniguchi K, et al. (2012) Periostin, a matrix protein plays a role in the induction of cytokines in pulmonary fibrosis. Am J Respir Cel Mol Biol 46: 677-86.

121. Hong LZ, Wei XW, Chen JF, Shi Y (2013) Overexpression of periostin predict poor prognosis in non-small cell lung cancer. Oncol Lett 6: 1595 -603.

122. Ishiba T, Nagahawa T, Sato T, Ishikawa T, Uetake H, et al. (2014) Periostin suppression induces decorin secretion leading to reduced breast cancer cell motility and invasion. Sci Rep 4: 7069.

123. Takashima K, Meguro K, Kawashima H, Kashiwakuma D, Kagami SI, et al. (2019) Serum periostin levels serve as both eosinophilic airway inflammation and fixed airflow limitation in well-controlled asthmatics. J Asthma 56: 236-43.

124. Matsuka K, Kabata H, Fukunaga K, Suzuki Y, Masaki K, et al. (2015) Phenotype of asthma related to high serum periostin levels. Allergol Int 64: 175-80.

125. Woodruff PG, Boushey HA, Dolganov GM, Barker CS, Yang YH, et al. (2007) Genome-wide profiling of identifies epithelial cell genes associated with asthma and with treatment to corticosteroids. Proc Natl Acad Sci 104: 15858-63.

126. Blanchard C, Mingler MK, McBridge M, Putman PE, Collins SMH, et al. (2008) Periostin facilitates eosinophil tissue infiltration in allergic lung and eosophageal responses. Mucosa Immunol 1: 289-96.

127. Nair P, Kraft M (2012) Serum periostin as a marker of eosinophilic inflammation. J Allergy Clin Immunol 130: 655-6.

128. Sehra S, Yao W, Nguyen ET, Ahyi AN, Tuana FM, et al. (2011) Periostin regulates goblet cell metaplasia in a model of allergic airway inflammation. J Immunol 186: 4959-66.

129. Bentley JK, Chen Q, Hosig JY, Popova AP, Lei J, et al. (2014) Periostin is required for maximal airway inflammation and hyperresponsiveness in mice. J Allergy Clin Immunol 134: 1433-42. 
130. Kanemitsu Y, Matsumoto H, Mishiba M, KiHAC Respiratory Medicine Group (2014) Factors contributing to an accelerated decline in pulmonary function. Allergol Int 63: 181-8.

131. Izuhara Y, Matsumoto H, Kanemitsu Y, Izuhara K, Tohda Y, et al. (2014) GLCC1 variant accelerates pulmonary function decline in patients with asthma receiving inhaled corticosteroids. Allergy 69: 668-73.

132. Kanemitsu Y, Ito I, Niimi A, Izuhara K, Ohta S (2014) Ostepontin and periostin are associated with a 20 -year decline of pulmonary function in patients with asthma. Am J Respir Crit Care Med 190: 472-4.

133. Kanemitsu Y, Matsumoto H, Izuhara K, Tohda Y, Kita H, et al. (2013) Increased periostin associates with greater airflow limitation in patients receiving inhaled corticosteroids. J Allergy Clin Immunol 132:305-12.

134. Sidhu SS, Yuan S, Innes AL, Kerr S, Woodruff PG, et al. (2010) Roles of epithelial cell-driven periostin in TGF-beta activation, collagen production, and collagen gel elasticity. Proc Natl Acad Sci USA 107: 14170-5.

135. Takayama G, Arima K, Kanaji T, Toda S, Tanaka H, et al. (2006) Periostin: a novel component of subepithelial fibrosis of bronchial asthma downstream of IL-4 and IL-13 signals. J Allergy Clin Immunol 118: 98-104.

136. Izuhara K, Ohta S, Ono J (2016) Using periostin as a biomarker in the treatment of asthma. Allergy Asthma Immunol Res 8: 491-8.

137. Matsumoto H (2014) Serum periostin: a novel biomarker for asthma management. Allergol Int 63: 153-60.

138. Li W, Gao P, Zhi Y, Xu W, Wu Y, et al. (2017) Periostin: its role in asthma and its potential as a diagnostic or therapeutic target. Repir Res 16: 57.

139. Nagasaki T, Matsumoto H, Kanemitsu Y, Izuhara K, Tohda Y, et al. (2014) Using inhaled nitric oxide and serum periostin as composite marker to identify severe/steroid-insensitive asthma. Am J Respir Crit Care Med 190: 1449-52.

140. Ultsch M, Bever J, Nakamura V, Vanlen R, Kelley RF, et al. (2013) Structural basis of signaling blockade by anti-IL-13 antibody lebrikizumab. J Mol Biol 425: 1330-9.

141. Schreen SH, Arron JR, Zheng Y, Putnam WS, Erickson RW, et al. (2014) Effect of lebrikizumab in patients with mild asthma following whole lung allergen challenge. Clin Exp Allergy 44: 38-46.

142. Hanania NA, Noonan M, Corren J, Korenblast P, Zheng Y, et al. (2015) Lebrikizumab in moderate-to-severe asthma: a pooled data from two randomized placebo-controlled studies. Thorax 70:748-56.

143. Hanania NA, Wenzel S, Rosén K, Hsieh HJ, Mosesova S, et al.(2013) Exploring the effects of omalizumab in allergic asthma: an analysis of biomarkers in the EXTRA study. Am J Respir Crit Care Med 187: 804-11.

144. Hanania NA, Musumi Y, Hayashi Y, Arakawa F (1992) Molecular cloning and sequence analysis of human dipeptidy peptidase IV, a serine protease on the cell surface. BiochBiophys Acta 1131: 333-6.

145. Havre PA, Abe M, Urasi Y, Ohnuma K, Morimoto C, et al. (2008) The role of CD26/dipeptidy peptidase IV in cancer. Front Biosci 13: 1634-45.

146. Velden VD, Wierenga-Wolf AF, Adriaansen-Soeting PW, Overbeek SE, Moller GM, et al. (1998) Expression of aminopeptidases N and dipeptidyl peptidase IV in healthy and asthmatic bronchus. Clin Exp Allergy 28: 110-20.

147. Emson C, Mantz SP, Newbold P (2018) Periostin and dipeptidyl peptidase-4 potential biomarkers of interleukin 13 pathway activation in asthma and allergy. Immunol Allergy Clin North Am 38: 611-28.

148. Wronkowitz N, GÖrgren SW, Romacho T, Villalobos LA, Sánchez-Ferrer CF, et al. (2014) Soluble DPP4 induces inflammation and proliferation of human smooth muscle cells via protease-activated receptor 2. BiochimBiophys Acta (BBA) 1842: 1613-21.

149. Shiobara T, Chibana K, Watanabe T, Arai R, Horigane Y, et al. (2016) Dipeptidyl peptidase-4 is highly expressed in bronchial epithelial cells of untreated asthma and it increases cell proliferation along with fibronectin production in airway constitutive cells. Respir Res 17: 28.

150. Lun SW, Wong CK,Fanny WSK, Hui DS, Lam CW (2007) Increased expression of plasma CD4+ T lymphocyte costimulating molecule CD26 in adult patients with allergic asthma. J Clin Immunol 27: 430-7.

151. Nieto-Fontarigo, Gonzalez-Barcala FJ, Jose ES, Arias P, Nogueira M, et al. (2019) CD26 and asthma: a comprehensive review. Clin Rev Allergy Immunol 56: 139-60.

152. Zhang T, Urbanek C, Burchard EG, Chu H, Seibold MA (2014) The asthma biomarker dipeptidyl peptidase 4 (dpp4) is IL-13 inducible in the airway epithelial cells and inhibits rhinovirus infection In: Presented at the American Thoracic Society 2014 International conference, San Diego, California,USA.

153. Brightling CE, Chanez P, Leigh R, O’Byrne PM, Korn S, et al. (2015) Efficacy and safety of tralokinumab in patients with severe uncontrolled asthma: a randomized, double-blind, placebo-controlled phase $2 \mathrm{~b}$ trial. Lancet Respir Med 3: 692-701.

154. James S, Kolmert J, Knowle S, Dahlen S-L (2016) Late-breakfast abstract: Lack of association between circulating dipeptidyl peptidase-4 and other biomarkers of asthma: data from U-BIOPRED and BIOAIR. Eur Respir J 48: PA1095.

155. Streicher K, Yao Y, Ranade K, Liang M, Vainshtein I, et al. (2015) Dipeptidyl peptidase (DPP-4/cc26) as a peripheral biomarker of IL-13 activation in asthmatic lung. EP3099323A1. European Patent Office, Europe.

156. Kim SH, Choi H, Yoon MG, Park HS (2015) Dipeptidyl peptidase 10 as a genetic biomarker for aspirin-exacerbated respiratory disease phenotype. Ann Allergy Asthma Immunol 114: 208-13.

157. Colice G, Price D, Vendier MG, Rabon-Stith K, Ambrose C, et al. (2017) The effect of DPP-4 inhibitors on asthma control: an administrative database study to evaluate a potential pathophysiological relationship. Pragmat Obs Res 8: 231-40.

158. Cordero OJ, Imbernon M, Chiara LD, Martinez-Zorzano VS, Ayude D, et al. (2011) Potential of soluble CD26 as a serum marker for colorectal cancer detection. World J Clin Oncol 2: 245-61.

159. Larrinaga G, Perez I, Sanz B, Beitia M, Errarte P, et al. (2015) Dipeptidyl peptidase IV activity is correlated with colorectal cancer prognosis. PLoS ONE 2015: 10.1371/ journal.pone.0119436.

160. Boccardi V, Maran OL, Rossetti RRA, Rizzo MR, di Martino N, et al. (2015) Serum CD26 levels in patients with gastric cancer: a novel potential diagnostic marker. BMC Cancer 15: 703 .

161. Sullivan SD, Wenzel SE, Bresnahan BW,Zheng B, Lee JH, et al. (2007) Association of control and risk of severe asthma - related events in severe or difficult-to-treat asthma. Allergy 62: 655-60.

162. Bateman ED, Boushey HA, Bousquet J, Busse WW, Clark TJ, et al. (2004) Can guideline-defined asthma control be achieved? The Gaining Optimal Control study. Am J Respir Crit Care Med 170: 836-44.

163. Bel EH, Sousa A, Fleming L, Bush A, Chung KF, et al. (2010) Diagnosis and definition of severe refractory asthma: an international consensus from the Innovative Medicine Initiative (IMI). Thorax 66: 10.1136/thx.2010.153643. 
164. Saini SS, MacGlasham DW, Sterbinsky SA, Togias A, Adelman DC, et al. (1999) Down-regulation of human basophil IgE and FC epsilon R1 alpha surface densities and mediator release by anti-IgE-infusions is reversible in vitro and vivo. J Immunol 162: 5624-30.

165. McCracken JL, Tripple JW, Calhoun WJ (2016) Biological therapy in the management of asthma. Curr Opin Clin Immunol 16: 375-82.

166. Humbert M, Beasley R, Ayres J, SlavinR, Hébert J, et al. (2005) Benefit of omalizumab as add-on therapy in patients with severe persistent asthma who are inadequately controlled despite best available therapy (GINA 2002 step 4) treatment: INNOVATE. Allergy 60: 309-16.

167. Busse W, Corren J, Lanier BQ, McAlary M, Flower-Taylor A, et al. (2001) Omalizumab, anti-IgE recombinant humanized monoclonal antibody for the treatment of severe allergic asthma. J Allergy Clin Immunol 108: 184-90.

168. Djukavonoc R, Wilson SJ, Kraft M, JarjourNN, Steel M, et al. (2004) Effects of treatment with anti-immunoglobulin E antibody omalizumab on airway inflammation in allergic asthma. Am J Respir Crit Care Med 170: 583-93.

169. Holgate ST, Chuchalin AG, Hébert J, Lötvall T, Parsson GB, et al. (2004) Efficacy and safety of a recombinant anti-immunoglobulin E antibody (omalizumab) in severe allergic asthma. Clin Exp Allergy 34: 632-838

170. Gnanakumaran G, Babu KS (2003) Technology evaluation: mepolizumab, GlaxoSmithKline. Curr Opin Med Ther 5: 321-5.

171. Leckie MJ, Brinke A, Khan J, Diamant J, Mathur AK, et al. (2000) Effects of an interleukin-5 blocking monoclonal antibody on eosinophils, airway hyperresponsiveness, and the late asthmatic response. Lancet 356: 2144-8.

172. Pavord ID, Korns S, Howarth P, Bleeker ER, Buhl L, et al. (2012) Mepolizumab for severe asthma (DREAM): a multicenter, double-blind, placebo-controlled trial. Lancet 380: 651-9.

173. Ortega HG, Liu MC, Brusselle GG, Fitzgerald JM, Chatta S, et al. (2014) Mepolizumab treatment in patients with severe eosinophilic asthma. N Engl J Med 371: 1198-207.

174. Bel EH, Wenzel SE, Thompson PJ, Prazma CM, Keene ON, et al. (2014) Oral glucocorticoid-sparing effect of mepolizumab in eosinophilic asthma. N Engl J Med 371: 1189-97.

175. Zhang J, Kuvelkar R, Murgolo NJ, Taremi SS,Chou C, et al. (1999) Mapping and characterization of the epitope(s) of Sch 55700, a humanized mAb, that inhibits human IL-5. Int Immunol 11: 1935-44.

176. Castro M, Mathur S, Hargreave F, Boulet L, Xie F, et al. (2011) Reslizumab for poorly controlled asthma: a randomized, placebo-controlled study. Am J Respir Crit Care Med 184: 1125-32.

177. Castro M, Zangrilli J, Wechsler ME, Bateman ED, Brusselle GG, et al. (2015) Reslizumab for inadequately controlled asthma with elevated blood eosinophil count: result from two multicenter, parallel, double-blind, randomized, placebo-controlled phase 3 trial. Lancet Respir Med 3: 355-66.

178. Corren J, Weinstein S, Janka L, Zangrilli J, Garin M (2016) Phase 3 study of reslizumab in patients with poorly controlled asthma: effects across a broad range of eosinophil counts. Chest 150: 799-810.

179. Bjermer L, Lemiere C, Maspero J, Weiss S, Zangrilli J, et al. (2016) Reslizumab for inadequately controlled asthma with elevated blood eosinophil level: a randomized phase 3 study. Chest 150: 789-98.

180. TEVA Pharmaceutical (2006) Cinqaero (reslizumab) $10 \mathrm{mg} / \mathrm{mL}$ concentrate for solution for infusion, EMC, UK.

181. Castro M, Wenzel SE, Bleecker R, Pizzichini E, Kuna P, et al. (2014) Benralizumab, an anti-interleukin 5 receptor a monoclonal antibody, versus placebo for uncontrolled eosinophilic asthma: a phase $2 \mathrm{~b}$ randomized dose-ranging study. Lancet 2: 879-90.

182. Laviolette M, Gossage DL, Gauvreau G,Leigh R, Olivenstein R, et al. (2013) Effect of benralizumab on airway eosinophil in asthmatic patients with sputum eosinophilia. J Allergy Clin Immunol 132: 1086-95.

183. Bleeker ER, Fizgerald JM, Chanez P, Papi A, Weinstein SF, et al. (2016) Efficacy and safety of benralizumab for patients with severe asthma uncontrolled with high-dose inhaled corticosteroids and long-acting $\beta$-agonists (SIROCCO): a randomized multi-centre, placebo-controlled phase 3 trial. Lancet 388: 2128 -41.

184. Fitzgerald JM, Bleecker ER, Nair P, Korn S, Ohta K, et al. (2016) Benralizumab, an anti-interleukin-5 receptor monoclonal antibody, as add-on treatment for patients with severe asthma, uncontrolled eosinophilic asthma (CALIMA): a randomized, double-blind, placebo-controlled phase 3 trial. The Lancet 6736: 1-14.

185. Fitzgerald JM, Bleeker ER, Menzie-s-Gowa, Zangrilli JG, Hirch I, et al. (2018) Predictors of enhanced response with benralizumab for patients with severe asthma: pooled analysis of the SIROCCO and CALIMA studies. Lancet Respir Med 6: 51-64.

186. Nair P, Wenzel S, Rabe KF, Bourdin A, Lugogo NL, et al. (2017) Oral glucocorticoid-sparing effect of benralizumab in severe asthma. N Engl J Med 375: 2448-58. 187. Ingram JL, Kraft M (2012) IL-13 in asthma and allergic disease: asthma phenotypes and targeted therapies. J allergy Clin Immunol 130: 829-42.

188. Chibona K, Trudeau JB, Mustovich AT, Hu H, Zhao J, et al. (2008) IL-13 induced increase in nitrite levels are increased in inducible nitric oxide synthase compared with effects on arginases in human primary bronchial epithelial cells. Clin Exp Allergy 38: 936-46.

189. Wenzel S, Ford L, Pearlman D, Spector S, Sher L, et al. (2013) Dupilumab in persistent asthma with elevated eosinophil levels. N Eng J Med 368: $2455-66$.

190. Wenzel S, Castro M, Corren J, Maspero J, Wang L, et al. (2016) Dupilumab efficacy and safety in adults with uncontrolled persistent asthma despite use of mediumto-high-dose inhaled corticosteroids plus long-acting agonist: a randomized double-blind placebo-controlled pivotal $2 \mathrm{~b}$ dose-ranging trial. Lancet $388: 31-44$.

191. Simpson EL (2017) Dupilumab improves general health-related quality-of-life in adults with moderate to severe atopic dermatitis: Pooled results from two randomized, controlled phase3 clinical trials. Dermatol Ther (Heidelb) 7: 243-8.

192. Panettieri R, Sjöbring U, Péterfly AM, Wessman P, Bowen K, et al. (2018) Tralokinumab for severe, uncontrolled asthma (STRATOS 1 and STRATOS 2): two randomized, double-blind, placebo-controlled, phase 3 clinical trials. Lancet Update 6: 511-25.

193. Wollenberg A, Howel MD, Guttman-Yassky, Silverberg JI, Kell C, et al. (2008) Treatment of atopic dermatitis with tralokinumab, an anti-IL-13 mAb. J Allergy Clin Immunol 143: 135-41.

194. Hanania NA, Korenblast P, Bateman ED, Kopecky P, Paggiaro P, et al. (2016) Efficacy and safety of lebrikizumab in patients with uncontrolled asthma (LAVOLTA I and LAVOLTA II): replicate, phase 3, randomized, double-blind, placebo-controlled trials. Lancet Respir Med 4: 781-96.

195. Corren J, Parnes JR, Wang L, Mo M, Griffths JM, et al. (2007) Tezepelumab in adults with uncontrolled asthma. N Engl J Med 377: $936-46$.

196. Roseti S, Corren J, Parnes, Mo M, Griffths J, et al. (2007) Late Breakfast Abstract - Efficacy and safety of tezepelumab in adults with severe asthma. A randomized phase 2b study. Eur Respir J 50: OA3189.

197. Lindén A (2001) Role of interleukin-17 and the neutrophil in asthma. Int Arch Allergy Immunol 126: 179-84.

198. Lindén A, Laun M, Anderson GK (2005) Neutrophils, interleukin-17A and lung disease. Eur Respir J 25: $159-72$. 
199. Syabbalo N (2020) Neutrophilic asthma: a complex phenotype of asthma. J Lung Pulm Respir Res 7: 18-24.

200. Yang EJ, Beck KM, Liao W (2018) Secukinumab in the treatment of psoriasis: patient selection and perspectives. Psoriasis 8: 75-82.

201. Foulkes AC, Warren RB (2019) Brodalumab in psoriasis: evidence to date and clinical potential. Drugs Context 8: 212570.

202. Masoli M, Fabian D, Holt D (2004) Global Initiative for Asthma (GINA) Program. The global burden of asthma: executive summary of the GINA Dissemination Committee report. Allergy 59: 469-78.

203. The Global Asthma Network (2014) Asthma may affectas many as334 million people. The Global Asthma Report, Auckland, New Zealand.

204. National Asthma Education and Prevention Program (2007) Expert Panel Report 3 (EPR 3): Guidelines for the Diagnosis and Management of Asthma - A Summary Report 2007. J Allergy Clin Immunol 120: S94-S138.

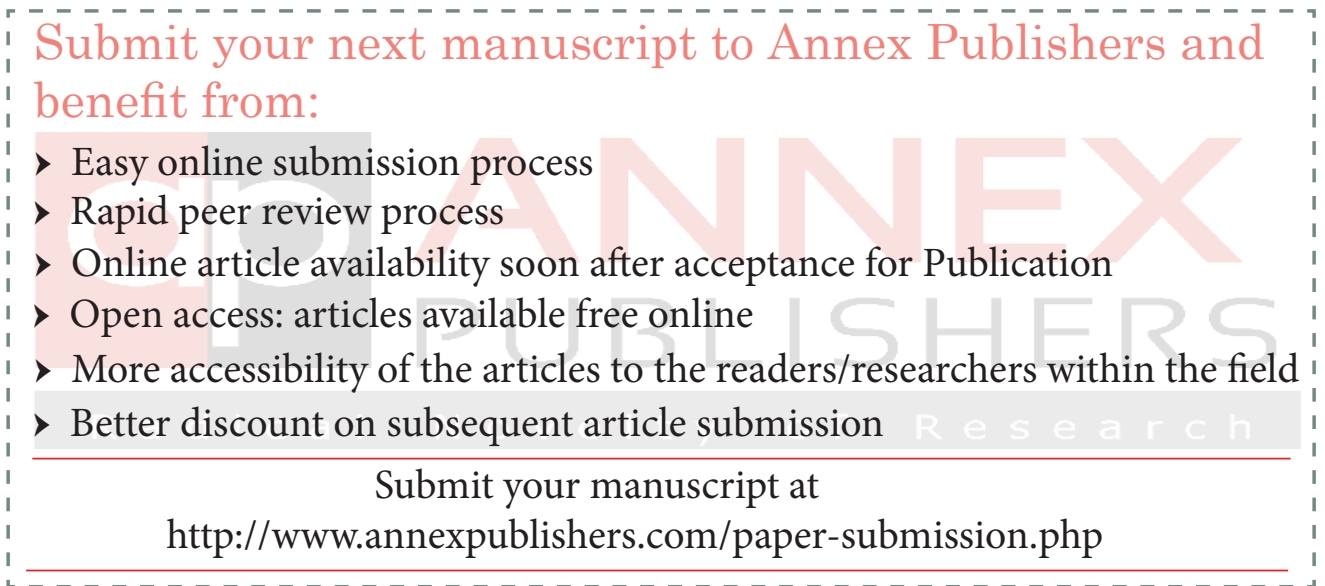

